\title{
HYPOEUTECTIC Al-Si ALLOY DOPED WITH CHROMIUM, TUNGSTEN AND MOLYBDENUM DESIGNATED FOR PRESSURE DIE CASTING
}

\begin{abstract}
Structural modification of hypoeutectic Al-Si alloy EN-AC 46000 alloy influences its microstructure and mechanical properties. In a series of examinations the EN-AC 46000 alloy has been doped with $\mathrm{Cr}, \mathrm{W}$ and Mo. The study involved the differential thermal analysis (DTA) and the light microscopy structural analysis of the samples cut from pressure die castings and from samples cast into the DTA cup. The DTA and microstructure analyses revealed new phases in the alloy doped with mentioned additives. The strength properties measurements of the alloys doped with $\mathrm{Cr}, \mathrm{W}$ and Mo showed significant improvement in tensile strength and elongation, while preserving good hardness.
\end{abstract}

Keywords: Multicomponent Al-Si alloys, pressure die casting, DTA method

\section{Introduction}

The production of light alloys based on aluminum and magnesium is growing systematically. In 2014 over 16 million tons of aluminum castings were produced, which accounted for approximately $15.5 \%$ of worldwide castings production. In comparison to the previous year, the production increased by about 1 million tons [1,2]. Aluminum alloys are often used in foundries, mainly because of their good casting properties, low density as well as relatively high mechanical properties. These properties can be increased by alloying additions, grain refinement and/or addition of foreign reinforced particles [3-6]. In aluminum alloys the following alloying elements can be distinguished: silicon ( $4 \mathrm{xxx}$ series), copper ( $2 \mathrm{xxx}$ series), magnesium ( $5 \mathrm{xxx}$ series) or zinc ( $7 x x x$ series). The promising properties have been shown alloys with lithium because of their low specific density and high mechanical properties obtained by the precipitation hardening. Very interesting results are shown in [7] where scandium was used as an alloying addition. In paper [8] grain size reduction by vanadium addition has been shown while modifying effect of molybdenum is shown in paper [9]. However, there is much less information in the literature concerning the possibility of increasing the mechanical properties of aluminum alloys through the addition of high-melting elements, such as chromium, vanadium, molybdenum or tungsten. These elements can create unlimited solutions (e.g. Cr-Mo, Cr-W or Mo-W) with each other, while in Al-Si alloys they create different intermetallic phases (e.g. $\mathrm{Fe}_{2} \mathrm{~W}, \mathrm{Cr}_{3} \mathrm{Si}$ ) with the constituent elements. According to the data presented in papers [10-16], aforementioned elements are characterized by the lack of solubility in aluminum in the solid state. Therefore, their simultaneous addition can cause a fragility of Al-Si alloys. However, the preliminary studies confirm the possibility of increasing the mechanical properties of Al alloys by high-melting elements. Accordingly, the aim of this paper was to investigate the effect of chromium, tungsten and molybdenum on the crystallization process, microstructure and mechanical properties of Al-Si alloy designated for pressure die casting technology.

\section{Experimental}

During the tests a EN-AC 46000 aluminum alloy was used. It is a typical hypoeutectic Al-Si alloy designed for pressure die casting, whose chemical composition is given in Table 1 . The alloy was melted in a gas shaft furnace with capacity of 1.5 tons. After smelting the alloy was refining inside the shaft furnace using a solid refiner Ecosal Al 113.S. After tapping, the molten alloy was poured into a ladle where it was deslagged. Then it was transported to the holding furnace placed near the IDRA $700 \mathrm{~S}$ pressure machine with a horizontal cold chamber. In the holding furnace AlCr15, AlW8 and AlMo8 master alloys were added to the melt of temperature amounted to $750^{\circ} \mathrm{C}$, which was then held by 30 minutes to assure complete dissolution of the master alloys. The alloy prepared in this way was used for castings of the housing roller blinds with predominant wall thickness of $2 \mathrm{~mm}$. In subsequent melts an amount of the master alloys addition was increased in order to obtain an increase by

\footnotetext{
* LODZ UNIVERSITY OF TECHNOLOGY, DEPARTMENT OF MATERIALS ENGINEERING AND PRODUCTION SYSTEMS, 1/15 STEFANOWSKIEGO STR., 90-924 ŁÓDŹ, POLAND

Corresponding author: tomasz.szymczak@p.lodz.pl
} 
0.05 wt. $\% \mathrm{Cr}, \mathrm{W}$ and Mo. The pressure die casting were made from alloys containing 0.00-0.25 wt.\% of Cr, W and Mo, and specimens cut from these castings were used during mechanical properties measurements.

TABLE 1

The chemical composition of EN-AC 46000 alloy

\begin{tabular}{|c|c|c|c|c|c|c|c|c|}
\hline \hline \multicolumn{10}{|c|}{ Chemical composition, wt.\% } \\
\hline Si & Fe & Cu & Mn & Mg & Cr & Ni & Zn & Ti \\
\hline 8.86 & 0.82 & 2.27 & 0.18 & 0.23 & 0.04 & 0.05 & 1.07 & 0.05 \\
\hline
\end{tabular}

The crystallization process was examined by differential thermal analysis (DTA) using alloys containing $0-0.35 \mathrm{wt} . \%$ of the mentioned additives and overheated to temperature of approx. $1100^{\circ} \mathrm{C}$. This surplus overheating enabled a pronounced demonstration of the additive elements effect on the temperatures of phase transformations. PtRh10-Pt thermocouple placed inside the DTA10-TUL resin-sand cup was used for recording the DTA curves - Figure 1 .

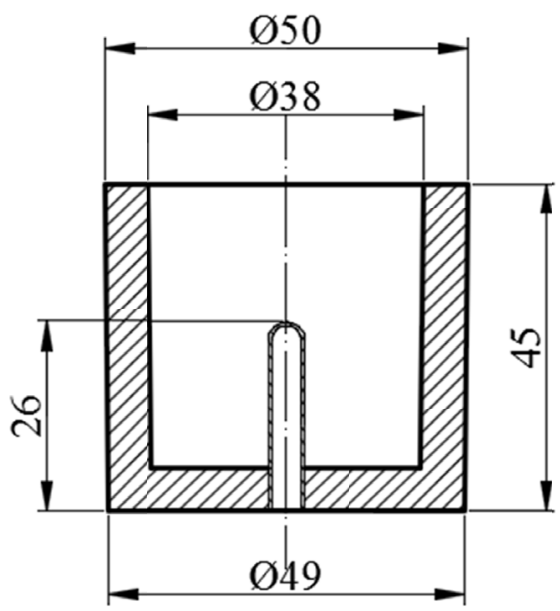

Fig. 1. Dimensions of DTA10-TUL cup

During the tests the tensile strength $R_{m}$, yield strength $R_{p 0.2}$ and elongation A were determined. Tensile tests were performed using Instron 3382 machine with a speed of $1 \mathrm{~mm} / \mathrm{min}$. Hardness tests were performed using ball-hardness tester machine HPO-2400. The ball of diameter $d=2.5 \mathrm{~mm}$ and a load of 613 $\mathrm{N}$ were used during the tests.

Alloys microstructure was investigated on specimens taken from pressure die castings and from DTA samples. Metallographic specimens were etched with $2 \%$ aqueous solution of HF and observed at magnification $100 \times$ for specimens from DTA experiments and at magnification $1000 \times$ for specimens from pressure die casting, using Nikon Eclipse MA200 microscope.

\section{Results and discussion}

Figures 2 and 3 show the DTA curves and microstructure of EN-AC 46000 alloy taken from DTA cup, respectively. There are three thermal effects on the derivative curve. The first thermal effect designated as PkAB comes from the crystallization of the solid solution $\alpha(\mathrm{Al})$ dendrites. The next thermal effect described as BEH comes from the triple eutectic $\alpha+\mathrm{Al}_{9} \mathrm{Fe}_{3} \mathrm{Si}_{2}+\beta$, while the HKL thermal effect corresponds to the quadruple eutectic $\alpha+\mathrm{Al}_{2} \mathrm{Cu}+\mathrm{AlSiCuFeMgMnNiTi}+\beta$.

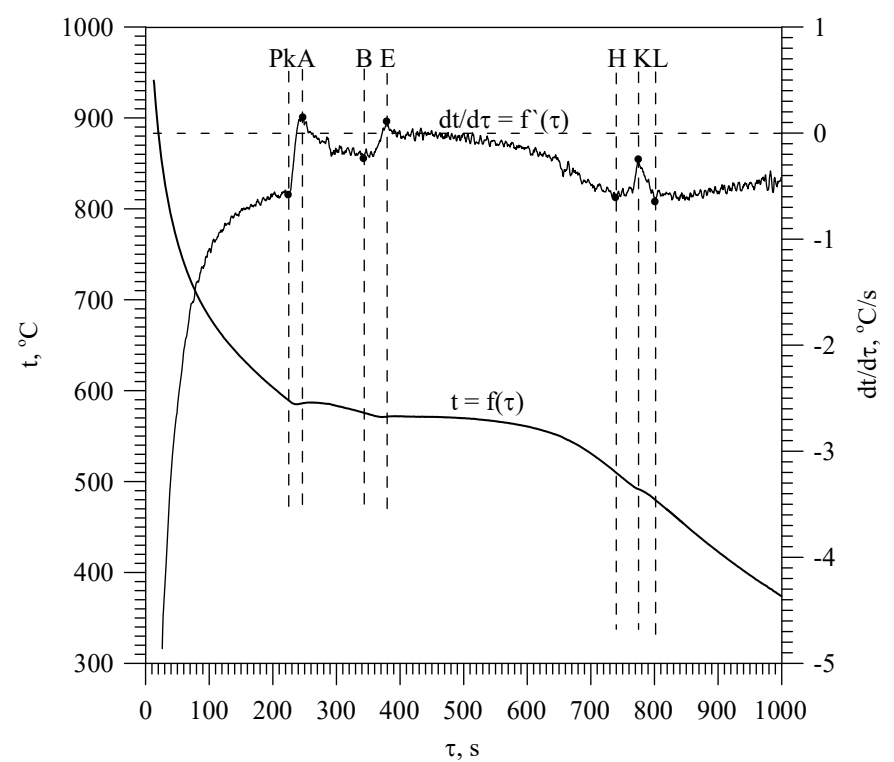

Fig. 2. DTA curves of EN-AC 46000 alloy

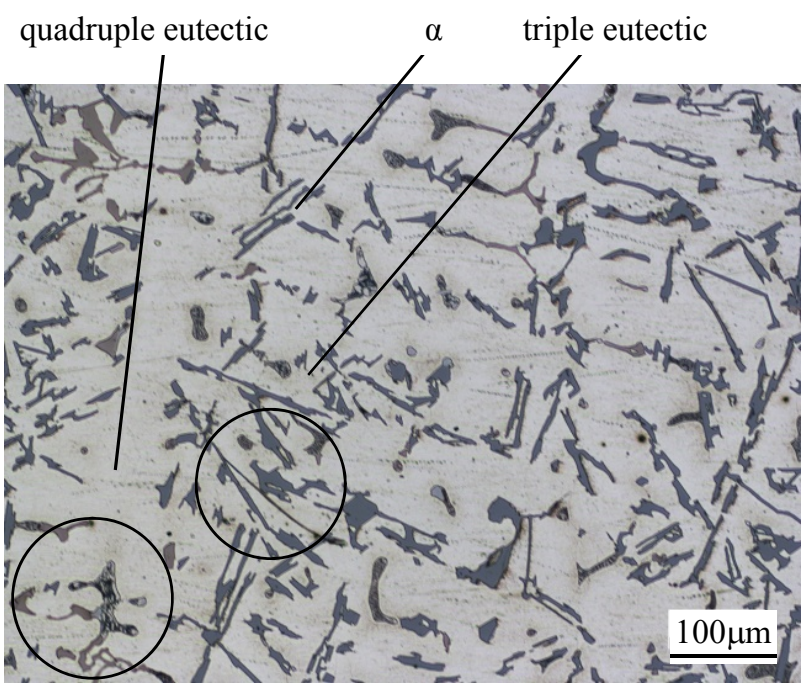

Fig. 3. Microstructure of EN-AC 46000 alloy obtained in the DTA experiment consisting of $\alpha, \alpha+\mathrm{Al}_{9} \mathrm{Fe}_{3} \mathrm{Si}_{2}+\beta$ and $\alpha+\mathrm{Al}_{2} \mathrm{Cu}+\mathrm{AlSi}-$ $\mathrm{CuFeMgMnNiTi}+\beta$ constituents

The microstructure of EN-AC 46000 alloy (Fig. 3) complies with the crystallization process described basing on the DTA curves (Fig. 2). Chromium, tungsten and molybdenum in an amount of approximately $0.05-0.20 \%$ did not change significantly DTA curves, which contain three similar thermal effects as obtained for the EN-AC 46000 alloy. The additives are probably bounded in the quadruple eutectic $\alpha+\mathrm{Al}_{2} \mathrm{Cu}+\mathrm{AlSiCuFeMgMn-}$ $\mathrm{NiTiCrWMo}+\beta$. In Figure 4 there are presented DTA curves of EN-AC 46000 alloy containing approximately $0.25 \% \mathrm{Cr}, \mathrm{W}$ 
and Mo. On these curves there is an additional thermal effect comparing with the DTA curves obtained for alloy without $\mathrm{Cr}$, $\mathrm{W}$ and Mo addition or containing up to $0.20 \mathrm{wt} \%$ of these additives. The new thermal effect designated as PkA"A' (Fig. 4) appears in the a higher temperature range than the $\mathrm{A}^{\prime} \mathrm{AB}$ effect caused by crystallization of $\alpha(\mathrm{Al})$ solid solution. The PkA"A' thermal effect is probably caused by peritectic crystallization of intermetallic phases containing $\mathrm{Cr}, \mathrm{W}$ and Mo. Other thermal effects seen on the mentioned curves are caused by triple (BEH effect) and quadruple (HKL effect) eutectic mixture crystallization. An increase in $\mathrm{Cr}$, Mo and $\mathrm{W}$ content up to 0.30 and 0.35 wt.\% resulted in the larger PkA"A' thermal effect. Figure 5 shows exemplary DTA curves of the examined alloy containing approximately $0.30 \mathrm{wt} . \%$ additives.

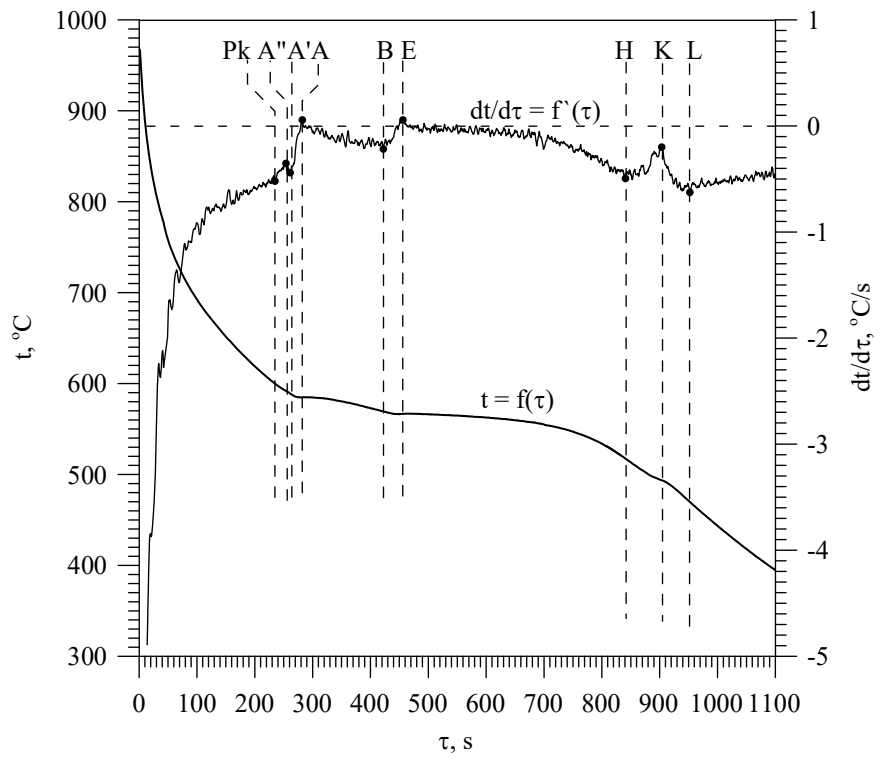

Fig. 4. DTA curves of the examined Al-Si alloy containing approx. 0.25 wt. \% Cr, Mo and W

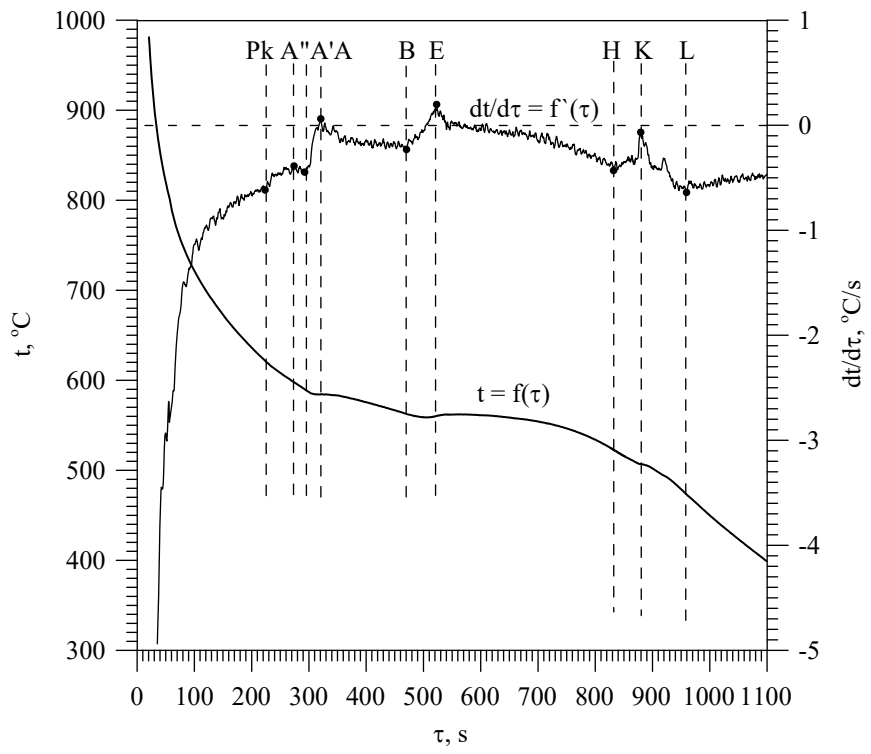

Fig. 5. DTA curves of the examined Al-Si alloy containing approx. $0.30 \% \mathrm{Cr}$, Mo and $\mathrm{W}$
TABLE 2

Values of the temperatures at the characteristic points

\begin{tabular}{|c|c|c|c|c|c|c|c|c|c|}
\hline \multirow{2}{*}{$\begin{array}{l}\text { Cr, } W \text { and } \\
\text { Mo, wt \% }\end{array}$} & \multicolumn{9}{|c|}{ Temperature t, ${ }^{\circ} \mathrm{C}$} \\
\hline & $\mathbf{P k}$ & A & $\mathbf{A}^{\prime}$ & A" & B & $\mathbf{E}$ & $\mathbf{H}$ & $\mathbf{K}$ & $\mathbf{L}$ \\
\hline 0.00 & 590 & 586 & - & - & 576 & 571 & 510 & 492 & 480 \\
\hline 0.05 & 593 & 586 & - & & 574 & 572 & 517 & 499 & 484 \\
\hline 0.10 & 604 & 590 & - & - & 576 & 574 & 503 & 495 & 480 \\
\hline 0.15 & 592 & 577 & - & - & 566 & 561 & 516 & 499 & 468 \\
\hline 0.20 & 593 & 582 & - & - & 564 & 558 & 519 & 498 & 475 \\
\hline 0.25 & 600 & 592 & 589 & 585 & 569 & 567 & 517 & 494 & 470 \\
\hline 0.30 & 622 & 598 & 590 & 584 & 563 & 560 & 523 & 507 & 473 \\
\hline .35 & 634 & 611 & 583 & 579 & 557 & 557 & 519 & 509 & 4 \\
\hline
\end{tabular}

TABLE 3

Values of the cooling rate at the characteristic points

\begin{tabular}{|c|c|c|c|c|c|c|c|c|c|}
\hline \hline \multirow{2}{*}{$\begin{array}{c}\text { Cr, W } \\
\text { and } \\
\text { Mo, \% }\end{array}$} & \multicolumn{10}{|c|}{$\boldsymbol{P k}$} & A & $\mathbf{A}^{\prime}$ & $\mathbf{A} \mathbf{~}^{\circ} \mathbf{C} / \mathbf{s}$ & $\mathbf{B}$ & $\mathbf{E}$ & $\mathbf{H}$ & $\mathbf{K}$ & $\mathbf{L}$ \\
\hline 0.00 & -0.58 & 0.15 & - & - & -0.24 & 0.11 & -0.61 & -0.25 & -0.64 \\
\hline 0.05 & -0.52 & 0.20 & - & - & -0.23 & 0.05 & -0.59 & -0.32 & -0.65 \\
\hline 0.10 & -0.66 & 0.13 & - & - & -0.26 & 0.08 & -0.69 & -0.32 & -0.72 \\
\hline 0.15 & -0.57 & 0.10 & - & - & -0.25 & 0.10 & -0.43 & -0.09 & -0.67 \\
\hline 0.20 & -0.55 & 0.04 & - & - & -0.25 & 0.08 & -0.50 & -0.18 & -0.66 \\
\hline 0.25 & -0.52 & -0.35 & -0.44 & 0.06 & -0.22 & 0.06 & -0.50 & -0.20 & -0.63 \\
\hline 0.30 & -0.62 & -0.39 & -0.45 & 0.06 & -0.23 & 0.20 & -0.43 & -0.07 & -0.64 \\
\hline 0.35 & -0.67 & -0.38 & -0.47 & 0.00 & -0.19 & 0.21 & -0.34 & 0.09 & -0.64 \\
\hline
\end{tabular}

The temperature values , $\mathrm{t}^{\prime \prime}$, and the cooling rate ,,$d t / d \tau$ ” in the characteristic points of each tested alloy are collected in Tables 2 and 3. The presented data show an unambiguous effect of chromium, tungsten and molybdenum on the characteristic points coordinates. The microstructure of the alloy containing $\mathrm{Cr}, \mathrm{W}$ and Mo poured into the DTA cup are shown in (Figure 6a-g). In the microstructure of alloys containing $\mathrm{Cr}$, Mo and $\mathrm{W}$, regardless of quantity, there are new phases which in EN-AC 46000 alloy did not occur. There are probably intermetallic phases containing the tested additives and coming from peritectic transformations. The amount of the "new" phases and their size increase with increasing $\mathrm{Cr}, \mathrm{W}$ and Mo addition. Dimensions of the new phases reach approx. 100 microns when the content of additives is approximately $0.05 \mathrm{wt} . \%$, however together with the increase of the additives content to $0.20 \%$ the phases grow to about 200 microns. Finally, when the content of Cr, Mo and W is in the range of $0.25-0.35 \mathrm{wt} . \%$ - the new phases have a dendritic morphology and their size increases with the increase in additive content from about 300 to more than 600 microns. The thermal effect PkA"A' (Figs. 4 and 5) probably appears in the alloys containing $0.25 ; 0.30$ and $0.35 \%$ additives due to crystallization of the phases having a relatively large size. This effect does not occur on the DTA curves of alloys with a lower content of Cr, Mo and W. This can be attributed to a small amount of heat released during the phases crystallization. The microstructure of the pressure die casting EN-AC 46000 alloy is shown in Figure 7. In this microstructure there are visible dendrites of the solid solution $\alpha$ separated with a relatively small thickness 
a)

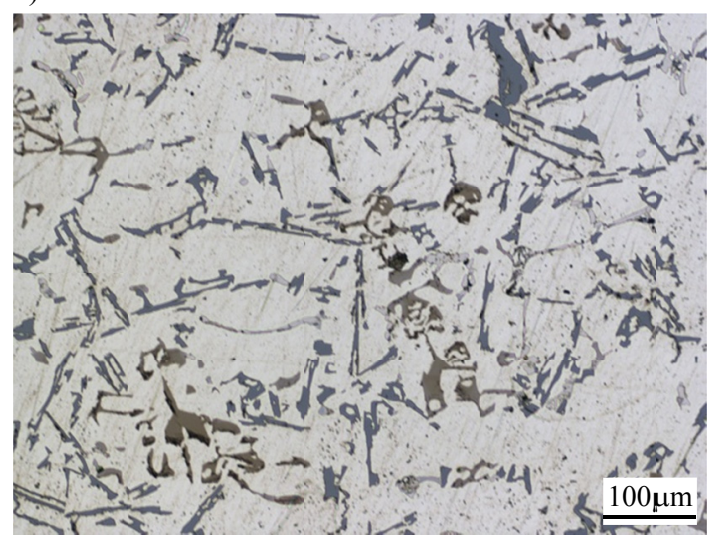

b)

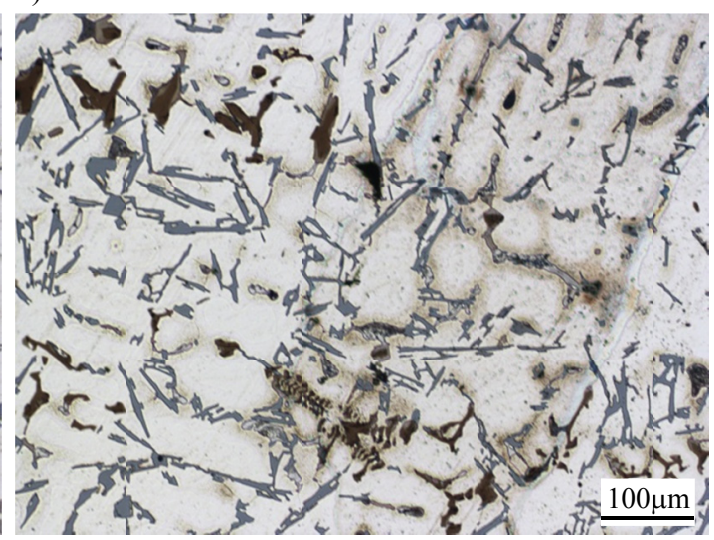

c)

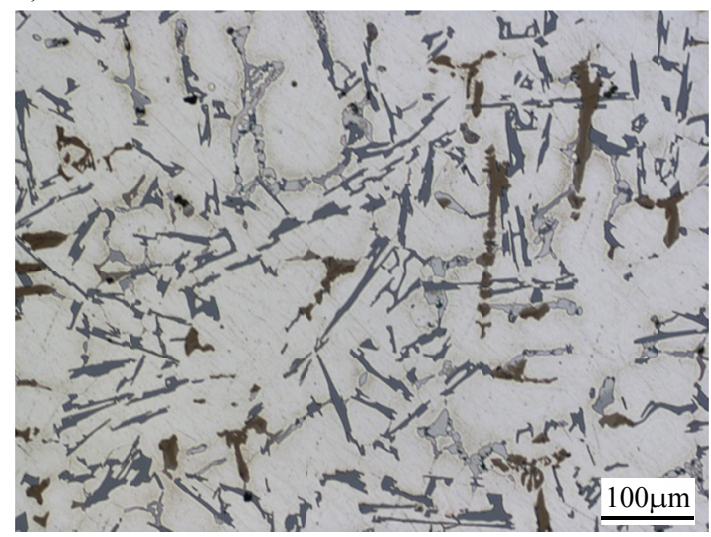

d)

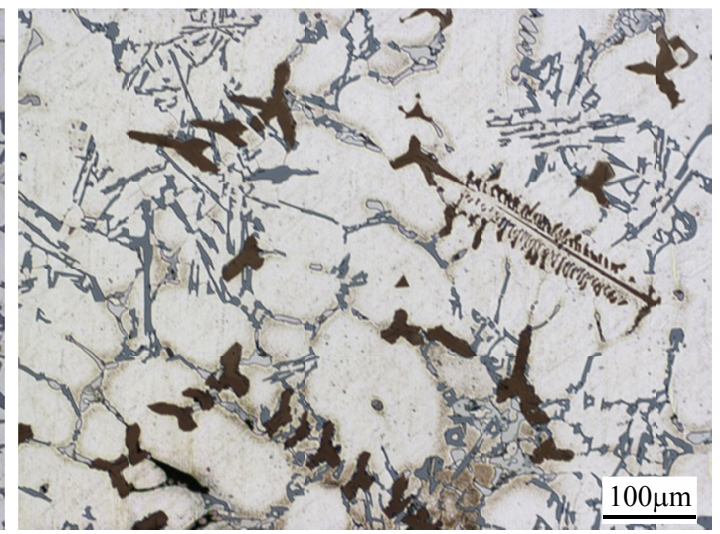

e)

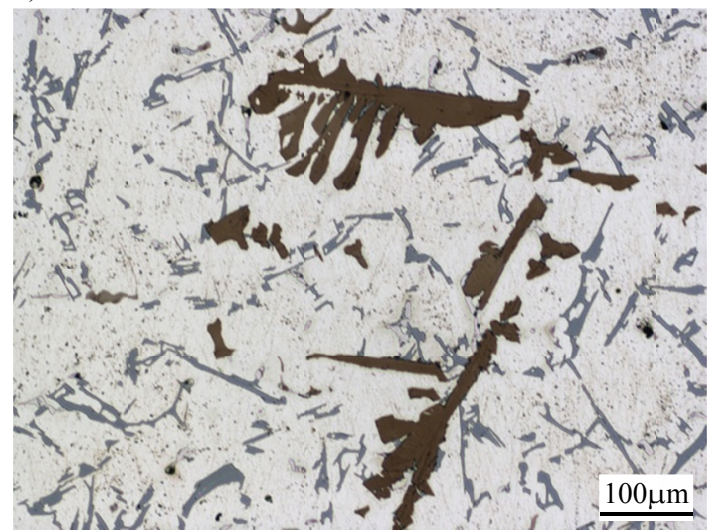

f)

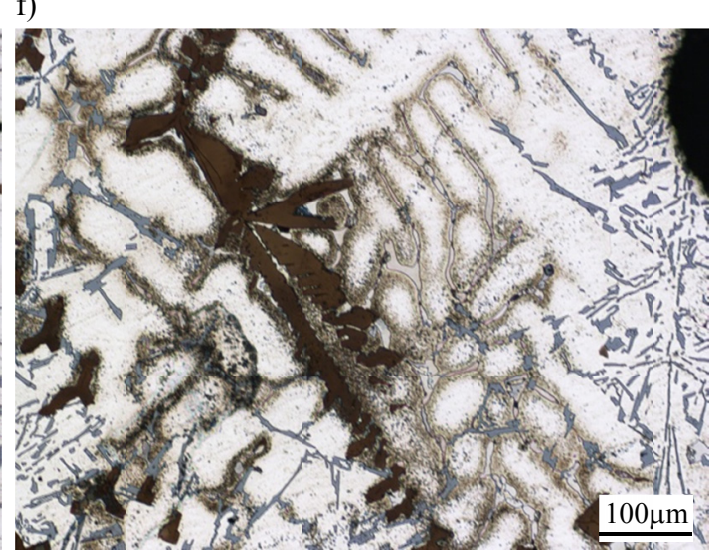

g)

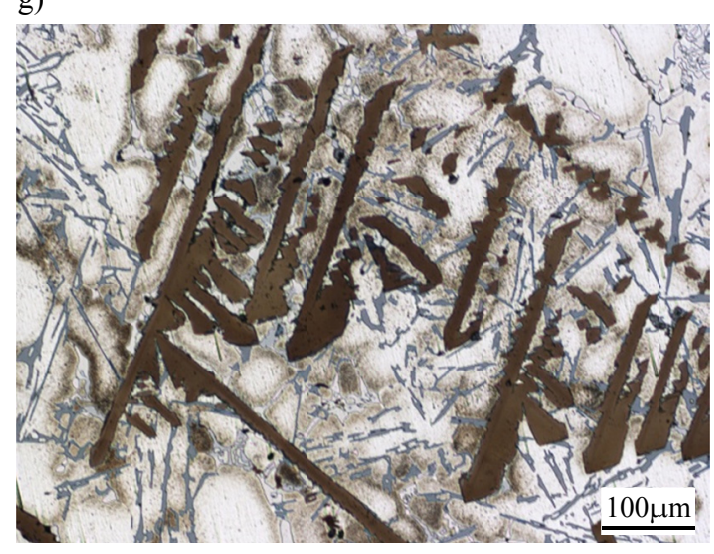

Fig. 6. Microstructure of the alloy with $\mathrm{Cr}$, Mo and $\mathrm{W}$ additives cast into DTA cup. The additives content, approximately: $\mathrm{a}-0,05$ wt.\%; $\mathrm{b}-0,10$ wt. $\%$; c-0,15 wt. $\%$; d-0,20 wt. $\%$; e - 0,25 wt. \%; f - 0,30 wt.\%; g-0,35 wt.\%. Microstructure constituents: $\alpha, \alpha+\mathrm{Al}_{9} \mathrm{Fe}_{3} \mathrm{Si}_{2}+\beta, \alpha+\mathrm{Al}_{2} \mathrm{Cu}$ $+\mathrm{AlSiCuFeMgMnNiTiCrWMo}+\beta$ 
of eutectic components. The microstructure of the pressure die casting alloy containing $\mathrm{Cr}, \mathrm{W}$ and $\mathrm{Mo}$ is presented in (Fig. 8a-e). The $\mathrm{Cr}, \mathrm{W}$ and Mo additives in pressure die casting alloy cause "new" phases growing, similarly as in the alloys cast into DTA cup. In pressure die casting, however, these phases have a walledmorphology. Their size increases with increasing content of the aforementioned additives, i.e. in the alloy containing approximately 0.05 wt. \% Cr, W and Mo it does not exceed 5 microns; in the alloy containing approximately $0.10 \mathrm{wt} . \%$ it increases to about 20 microns. Further increasing of additives amount to 0.15 ,
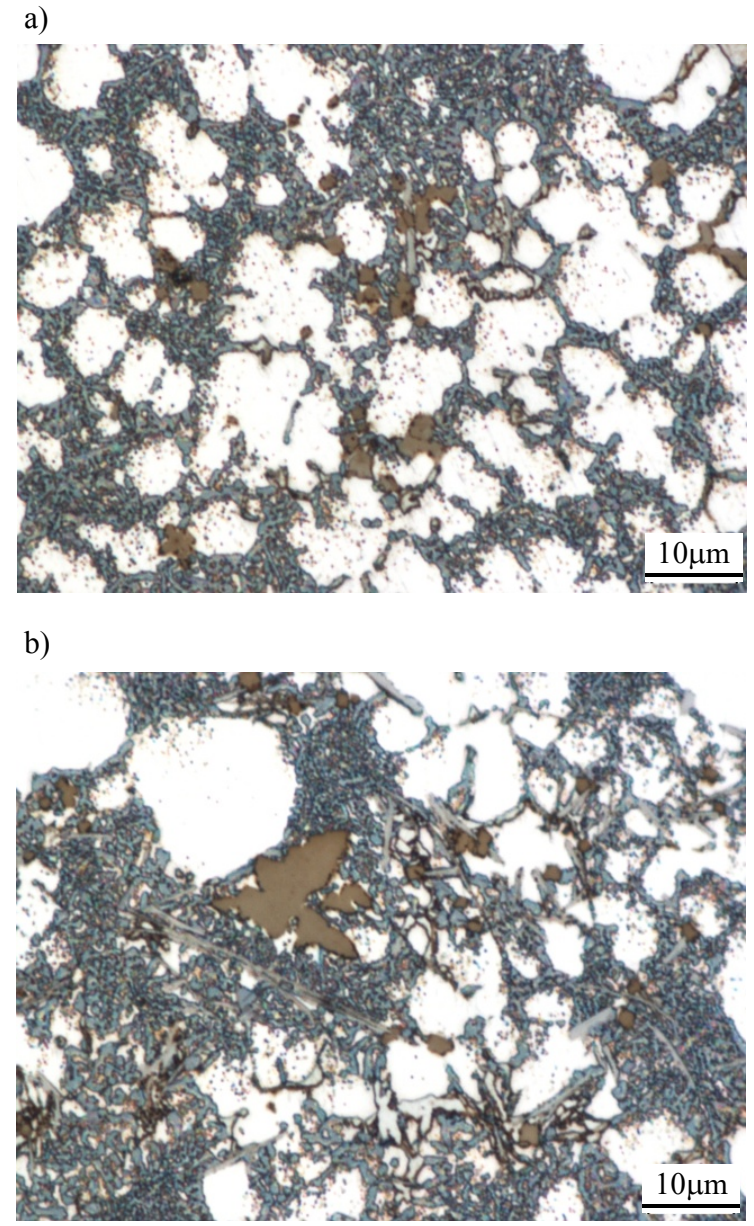

c)

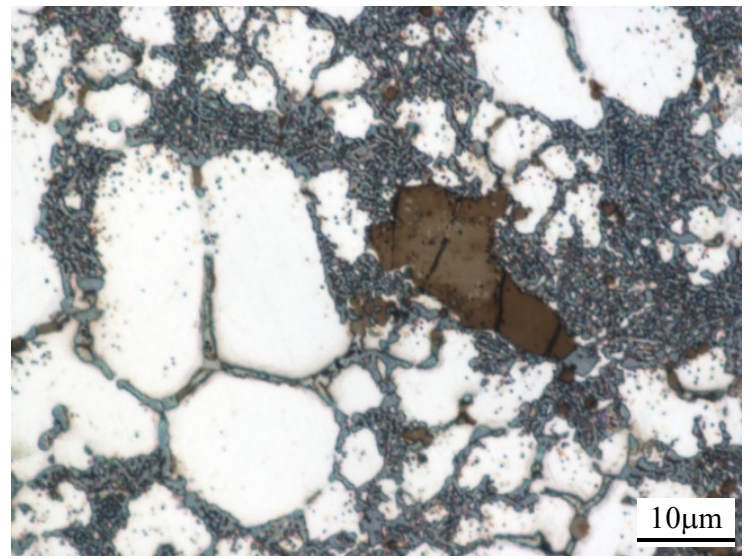

d)

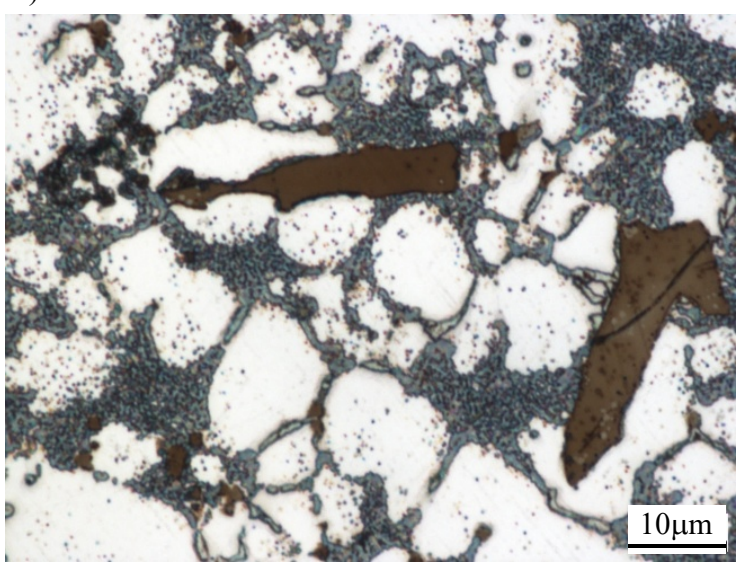

e)

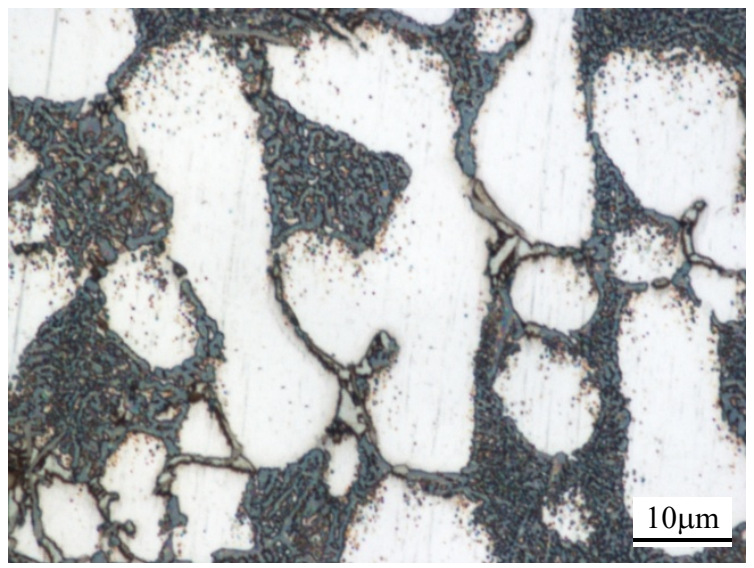

Fig. 7. Microstructure of the EN-AC 46000 pressure die casting alloy. Microstructure constituents: $\alpha, \alpha+\mathrm{Al}_{9} \mathrm{Fe}_{3} \mathrm{Si}_{2}+\beta, \alpha+\mathrm{Al}_{2} \mathrm{Cu}+\mathrm{AlSi}-$ $\mathrm{CuFeMgMnNi}+\beta$

Fig. 8. Microstructure of the pressure die casting alloy containing $\mathrm{Cr}, \mathrm{W}$ and Mo additives in amount of approximately: a -0.05 wt.\%; b -0.10 wt. $\%$; $\mathrm{c}-0.15$ wt. $\%$; d -0.20 wt. $\%$, e -0.25 wt. $\%$. Microstructure constituents: $\alpha, \alpha+\mathrm{Al}_{9} \mathrm{Fe}_{3} \mathrm{Si}_{2}+\beta, \alpha+\mathrm{Al}_{2} \mathrm{Cu}+\mathrm{AlSiCuFeMgMn}$ $\mathrm{NiTiCrWMo}+\beta$ 
0.20 and 0.25 wt.\% increases the maximum size of the "new" phases to about 30,35 and 60 microns, respectively.

The basic mechanical properties of the pressure die casting alloys are collected in Table 4 . The presented data indicate that EN AC-46000 alloy has a tensile strength $R_{m}=228 \mathrm{MPa}$; yield strength $R_{p 0.2}=111 \mathrm{MPa}$, elongation $\mathrm{A}=2.8 \%$ and $\mathrm{HB}=116$. The tensile strength and elongation versus $\mathrm{Cr}, \mathrm{W}$ and Mo content are presented in (Fig. 9a,b), respectively.

TABLE 4

Mechanical properties of EN-AC 46000 alloy with and without Cr, $\mathrm{W}$ and Mo additions

\begin{tabular}{|c|c|c|c|c|}
\hline \hline \multirow{2}{*}{$\begin{array}{c}\text { Cr, W } \\
\text { and Mo, } \\
\text { wt\% }\end{array}$} & \multicolumn{4}{|c|}{ Mechanical properties } \\
\cline { 2 - 5 } & $\boldsymbol{R}_{\boldsymbol{m}}$, MPa & $\boldsymbol{R}_{\boldsymbol{p 0 , 2},}, \mathbf{M P a}$ & $\mathbf{A}, \mathbf{\%}$ & HB \\
\hline 0.00 & 228 & 111 & 2.8 & 116 \\
\hline 0.05 & 245 & 122 & 3.7 & 109 \\
\hline 0.10 & 263 & 115 & 4.7 & 110 \\
\hline 0.15 & 265 & 110 & 5.9 & 106 \\
\hline 0.20 & 262 & 119 & 5.5 & 116 \\
\hline 0.25 & 222 & 98 & 3.2 & 110 \\
\hline
\end{tabular}

The data presented in Table 4 and in Fig. 9 show increasing of $R_{m}$ and A up to 0.15 wt.\% addition of $\mathrm{Cr}, \mathrm{W}$ and Mo $\left(R_{m}=265 \mathrm{MPa}, \mathrm{A}=5.9 \%\right)$. Further increasing of the additives amount causes decreasing of the examined properties. It follows that the tensile strength increases by about $16 \%$ in relation to the alloy without the additives while the elongation increases by more than $100 \%$. The initial increase in $R_{m}$ as well as A can be caused by saturation of the solid solution $\alpha$ with $\mathrm{Cr}, \mathrm{W}$ and Mo. This situation can occur during rapid solidification of the thin-walled pressure die castings. In contrast, the decrease in the $R_{m}$ and A occurring at relatively high contents of $\mathrm{Cr}, \mathrm{W}$ and $\mathrm{Mo}$ may be caused by a quite large dimensions of their intermetallic phases. The additives did not cause any increase in hardness, while the maximum increase in the yield strength does not exceed $10 \%$ and for this reason the changes of $R_{p 0.2}$ and HB can be considered as insignificant.

a)

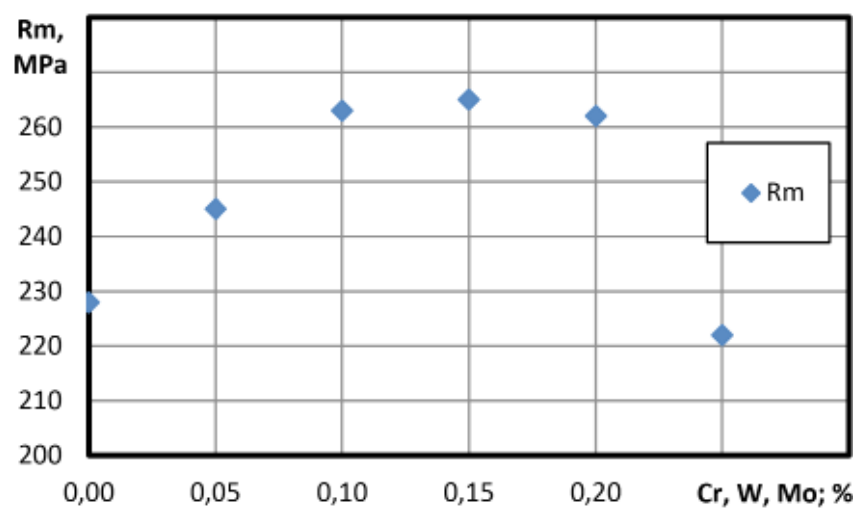

\section{Conclusions}

Basing on the results presented in this paper the following conclusions can be drawn:

- there are three thermal effects on the DTA curves of EN-AC 46000 alloy without $\mathrm{Cr}, \mathrm{W}$ and Mo additives and containing $0.05 ; 0.10 ; 0.15$ and 0.20 wt. $\% \mathrm{Cr}, \mathrm{W}$ and Mo. These thermal effects are connected with crystallization of $\alpha(\mathrm{Al})$ phase and triple and quadruple eutectic mixtures,

- $\quad$ on the DTA curves of the examined alloy containing 0.25 ; 0.30 and $0.35 \% \mathrm{Cr}, \mathrm{W}$ and Mo addition there is visible an additional thermal effect (PkA"A'), probably coming from crystallization of the intermetallic phases containing aforementioned additives,

- in microstructures of the alloys containing $\mathrm{Cr}, \mathrm{W}$ and $\mathrm{Mo}$, cast both into the DTA cup and into the pressure die there are visible "new" phases which did not occur in the EN AC-46000 alloy,

- $\quad \mathrm{Cr}, \mathrm{W}$, and Mo additives can significantly increase elongation and tensile strength of the examined Al-Si alloy.

\section{Acknowledgements}

Project co-financed by the European Regional Development Fund under the Operational Programme Innovative Economy in 2013-2015 according to the agreement No. UDA-POIG.01.04.00-10-079/12.

\section{REFERENCES}

[1] $48^{\text {th }}$ Census of World Casting Production. Mod. Cast., December 2014, 17-21.

[2] $49^{\text {th }}$ Census of World Casting Production. Mod. Cast., December 2015, 26-31.

[3] W. Krajewski, Arch. Metall. Mater. 44, 51-64 (1999).

[4] W.K. Krajewski, J. Lelito, J. S. Suchy, P. Schumacher, Arch. Metall. Mater. 54, 335-338 (2009).

b)

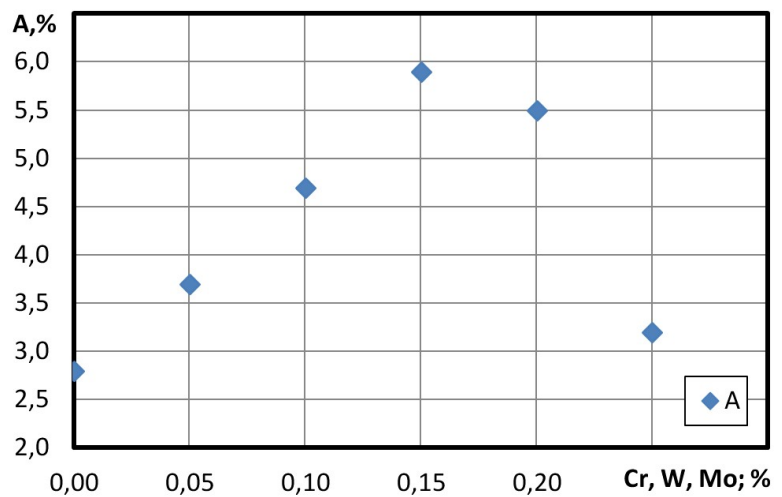

Fig. 9. Changes in the mechanical properties of EN-AC 46000 alloy with and without $\mathrm{Cr}, \mathrm{W}$ and Mo additions: $\mathrm{a}-$ tensile strength $R_{m}, \mathrm{~b}-\mathrm{elon}-$ gation $\mathrm{A}$ 
[5] J. Lelito, P.L. Żak, A.L. Greer, J.S. Suchy, W.K. Krajewski, B. Gracz, M. Szucki, A.A. Shirzadi, Composites Part B - Engineering 43, 3306-3309 (2012).

[6] W.K. Krajewski, A.L. Greer, P.K. Krajewski, Arch. Metall. Mater. 58, 845-847 (2013).

[7] K. Youssef, A. Zaddach, Ch. Niu, D. Irving, C. Koch, Mater. Res. Lett. 3 (2), 95-99, (2015)

[8] http://www.diva-portal.org/smash/get/diva2:649701/FULLTEXT01.pdf

[9] http://iopscience.iop.org/article/10.1088/1757-899X/60/1/012052/ pdf

[10] F. Binczyk, J. Piątkowski, Archives of Foundry 3(9), 39-44 (2003).

[11] K.L. Sahoo, B.N. Pathak, Journal of Materials Processing Technology 209, 798-804 (2009).
[12] K.L. Sahoo,S.K. Das, B.S. Murty, Mater. Sci. Eng. 355 (1-2), 193-200 (2003).

[13] S. Pietrowski, R. Władysiak, B. Pisarek, Crystallization, structure and properties of silumins with cobalt, chromium, molybdenum and tungsten admixtures. In International Conference Light Alloys and Composites, 13-16 May 1999 (77-83) (1999).

[14] S. Pietrowski, R. Władysiak, B. Pisarek, Solidification of Metals and Alloys 13, 103-108 (1998).

[15] S. Pietrowski, T. Szymczak, B. Siemińska-Jankowska, A. Jankowski, Archives of Foundry Engineering 10 (2), 107-126 (2010).

[16] S. Pietrowski, T. Szymczak, Modification of silumins with alloying elements. In S. Pietrowski (Eds.), Tendencies of optimization of the production system in foundries. (pp. 277-290). Katowice-Gliwice: Polish Academy of Sciences, Foundry commission. (in Polish) (2010). 